\title{
Redes sociales, agenda noticiosa y línea editorial durante hechos violentos en las protestas de 2017 en Venezuela*
}

[Artículos]

Irama Flores ${ }^{* *}$

Recibido: 30/04/2020

Aprobado: 4/11/2020

Citar como:

Flores, I. (2021). Redes sociales, agenda noticiosa y línea editorial durante hechos violentos en las protestas de 2017 en Venezuela. Análisis, 53(98).

https://doi.org/10.15332/21459169/5758

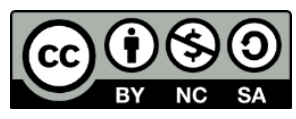

\section{Resumen}

Las redes sociales se han convertido en un mecanismo de información, recreación y de opinión para los usuarios de este tipo de plataformas virtuales; precisamente, se trata de las tres funciones de la comunicación social tradicionales. También las redes son una herramienta que los medios tienen en cuenta a la hora de tomar la decisión sobre qué o cuál es la noticia del momento. El estudio giró en torno a la agenda noticiosa imperante durante las protestas de 2017 en Venezuela con base en redes sociales y respaldada por géneros periodísticos, así como la relación

\footnotetext{
* Artículo de investigación.

** Doctora en Ciencias Gerenciales de la Universidad Experimental de la Fuerza Armada Nacional (UNEFA), Venezuela. Miembro de Investigadores Venezolanos de la Comunicación (INVECOM). Correo electrónico: iramamilei@gmail.com. ORCID: https://orcid.org/0000-0001-6842-3470
} 
entre dignidad humana y la forma como se presentaron noticiosamente los hechos violentos con víctimas fatales. Se estudiaron los diarios $E l$ Universal y El Nacional, en su versión digital, mediante fichas de precisión en las noticias relacionadas a 7 hechos con víctimas fatales de las protestas. Se concluye que, en algunas informaciones divulgadas por estos periódicos, se citaron algunos tuits, y se colgaron fotos y videos que habían circulado en las redes. Además, en algunos de los casos estudiados, estos medios incurrieron en difundir videos y fotografías de los hechos que reproducían el momento en el cual las víctimas fallecían, lo que define una agenda noticiosa sensacionalista, comercial y de irrespeto.

Palabras clave: redes sociales, noticias, ciberagenda, política editorial digital

\section{Social networks, news agenda and editorial line during violent events of the 2017 protests in Venezuela}

\section{Abstract}

Social networks have become a mechanism for information, recreation, and opinion for users of this type of virtual platforms; precisely, these are the three functions of traditional social communication. Networks are also a tool that the media takes into account when deciding what is the news of the moment. The study revolved around the prevailing news agenda during the 2017 protests in Venezuela based on social networks and supported by journalistic genres, as well as the relationship between human dignity and the way violent events with fatalities were reported. The newspapers El Universal and El Nacional, in their digital version, were studied by means of precision cards in the news related to 7 events involving fatal victims of the protests. It is concluded that, in some information released by these newspapers, some tweets were quoted, and photos and videos that had circulated in the networks were posted. Furthermore, in some of the cases studied, these media spread videos 
and photographs of the events that reproduced the moment in which the victims died, which defines a sensationalist, commercial and disrespectful news agenda.

Keywords: social networks, news, cyber agenda, digital editorial policy.

\section{Redes sociais, agenda de notícias e linha editorial durante eventos violentos nos protestos de 2017 na Venezuela}

\section{Resumo}

As redes sociais tornaram-se um mecanismo de informação, recreação e opinião para usuários desse tipo de plataformas virtuais; precisamente, estas são as três funções tradicionais da comunicação social. As redes também são uma ferramenta que a mídia leva em conta ao tomar a decisão sobre o que ou quais são as notícias do momento. O estudo girou em torno da agenda de notícias que prevaleceu durante os protestos de 2017 na Venezuela com base nas mídias sociais e apoiadas por gêneros jornalísticos, bem como a relação entre a dignidade humana e a forma como eventos violentos com fatalidades foram apresentados numa reportagem. Os jornais El Universal e El Nacional foram estudados, em sua versão digital, por meio de fichas de precisão nas notícias relacionadas a 7 eventos com vítimas fatais dos protestos. Conclui-se que, em algumas informações divulgadas por esses jornais, alguns tweets foram citados e fotos e vídeos que circularam nas redes foram postados. Além disso, em alguns dos casos estudados, esses meios de comunicação incorreram na divulgação de vídeos e fotografias dos eventos que reproduziram o momento em que as vítimas morreram, o que define uma agenda sensacionalista, comercial e desrespeitosa.

Palavras-chave: redes sociais, notícias, cyberagenda, política editorial digital. 


\section{Introducción}

En marzo del 2017, a través de las sentencias 155 y 156, el Tribunal Supremo de Justicia (TSJ) determinó que las funciones de la Asamblea Nacional (AN), por encontrarse en desacato, eran asumidas por el máximo órgano judicial del país, con lo que cesó legalmente la operatividad de la AN. La situación desencadenó una serie de críticas, marchas y concentraciones convocadas por los partidos opuestos al Gobierno en el este de Caracas y las ciudades capitales del resto del país. Inclusive, se generó un conflicto entre poderes (judicial y moral); la entonces fiscal general de la República de Venezuela declaró que la sentencia significaba "una ruptura del orden constitucional" (Ferreira, 2017).

Luego de ese episodio, y pese a la aclaratoria y corrección de las sentencias por parte del TSJ (“TSJ de Venezuela aclara...”, 2017), un grupo de ciudadanos siguió en las calles en respuesta al llamado de los partidos opuestos al Gobierno, los cuales no solo usaban los medios de comunicación social tradicionales, sino también las redes sociales.

Los llamados plantones o cierres de calles, procesiones religiosas, paro del comercio y el transporte, combinados con barricadas, saqueos, enfrentamientos entre fuerzas del orden y civiles e incluso civiles contra civiles, o simplemente de personas inocentes que transitaban por escenarios de la conflictividad, así como ataques a edificios de la administración pública, se prolongaron hasta el mes de julio de 2017. En el 2017, Bracci afirmó que unas 131 personas fallecieron desde inicio de las protestas en marzo hasta el 27 de julio de 2017. Para otros, la cifra de fallecidos llegó a 163 y se "contabiliza 6729 manifestaciones desde el $1 .^{\circ}$ de abril hasta el 31 de julio de 2017 en todo el país, equivalente a 56 protestas diarias" (Observatorio Venezolano de Conflictividad Social, 2017). 
Todos estos hechos contaron con una amplia cobertura por parte de los medios de comunicación social, con el apoyo de las redes sociales, las cuales cumplieron el papel de recopilar y difundir en forma casi inmediata cada una de las situaciones, especialmente las violentas. A través de ellas se divulgaron las imágenes (fotos y videos) que eran reenviadas a la mayor cantidad de ciudadanos posibles y que, incluso, fueron recogidos por las cuentas oficiales de los medios tradicionales, para la difusión virtual de los hechos acontecidos. Un estudio periodístico sobre lo anterior ("Así se vive en las redes...”, 2017) da cuenta de esta afirmación al hacer una recopilación de las manifestaciones y hechos relacionados, basado en redes sociales como Twitter e Instagram.

Y es que las redes sociales, con sus mensajes sobre todo en forma de imágenes, llegan a un gran número de venezolanos si se considera la alta penetración de internet. En el 2015, Conatel aseguró que, en Venezuela, la internet abarca a una población de 16728894 habitantes, que representa el 62.48 \% de la población; esto es más de la mitad de los venezolanos con acceso a la red de redes. En cuanto las redes sociales más usadas en el país resaltan Facebook y Twitter. Yapur (2015) confirma que 9 de cada 10 personas tiene una cuenta en Facebook y 7 de cada 10 tiene un usuario en Twitter.

Es cierto que las redes virtuales difunden múltiples mensajes en tiempo casi real, lo que se convierte en un atractivo para los medios de comunicación porque pueden servir de temáticas para la agenda noticiosa; sin embargo, es imprescindible el tratamiento profesional de lo recibido, es decir, contrastar fuentes y la vigilancia de valores éticos. La divulgación, por ejemplo, de mensajes insensibles no solo violenta la dignidad e irrespeta a quienes los reciben, sino que devela un tipo de medios sin compasión por parte de quienes tienen la responsabilidad de dirigir estos instrumentos. 
$\mathrm{Al}$ respecto, Izarra y López (2010) explican que los medios sufren la gran presión del rating o captación de audiencias. Se orientan por el dicho anglosajón: If it bleeds, it leads ("si sangra, encabeza"), es decir, entre más violento es un hecho, más oportunidad tiene de ser difundido.

Abad (2010) explica que los medios "venden como noticia su evangelio de violencia y desgracia cotidiana; comercializan huracanes, terremotos, sequías, balaceras, traiciones, corrupción y terrorismo mediático depurado como producción de espejismos, ante las miradas atónitas de la población [...]" (p. 127). Martín Barbero (1998) comparte este anterior punto de vista y analiza que la información, su proceso de elaboración, es lo más parecido a un programa de telerrealidad, un espectáculo en el cual lo menos importante es la investigación, el análisis y la argumentación, sino su teatralidad o el sensacionalismo. La afirmación de Martín Barbero (1998) se vincula a la línea editorial, que para este trabajo se define como guía filosófica, política, social, económica y hasta religiosa, la cual condiciona al medio a la hora de abordar y difundir informaciones.

En ese orden, los medios informativos siguen una agenda noticiosa, una línea editorial como orientación para la cobertura y difusión (basada en intereses particulares del medio), y reconocen que en el presente las redes sociales poseen una amplia capacidad de penetración y masificación de los mensajes casi desde el momento en el cual se producen los hechos y luego de las protestas del 2017 en Venezuela, con el resultado lamentable de más de 100 individuos fallecidos.

A partir de lo anterior, surgen los siguientes interrogantes: ¿̇en qué medida los temas noticiosos se retoman o no en la agenda noticiosa desde el punto de vista del periodismo durante las protestas de 2017 en Venezuela? ¿Qué tipo de géneros periodísticos utilizaron los medios para tratar los hechos difundidos en primera instancia por las redes sociales? ¿Qué papel desempeñó el periodismo en el resguardo de la dignidad humana y la 
forma en que se divulgaron los hechos catalogados como violentos y con víctimas fatales? Las respuestas a estas interrogantes son respondidas de forma reflexiva en esta investigación.

\section{Fuentes, verdad y posverdad}

Martínez y Osorio (2004) definen una fuente informativa de la siente manera:

[...] cualquier persona, institución, colectivo o documento que ayuda al periodista en su labor profesional. Normalmente tiene dos grandes usos: o bien proporciona al periodista datos a partir de los cuales puede existir un indicio de noticia o se puede originar una noticia o bien le sirve al periodista para enriquecerse, completar o ilustrar su información. (Martínez y Osorio, 2004, p. 263)

Una fuente de información periodística es aquella capaz de brindar información sobre hechos ocurridos. Es tomada como testimonio válido (fuentes directas) para ser insertada como base de las noticias que son dadas a conocer a los públicos.

El problema con la fuente y los mensajes podría surgir cuando aquella miente. Al respecto, el periodista Javier Darío Restrepo, durante una presentación en el I Congreso Nacional de Comunicadores Católicos, celebrado en Paraguay en el año 2009, sobre la fiabilidad de la fuente señaló “[...] que dependerá de cada usuario investigar si es verdad o no, porque como toda fuente hay que dudar de ella" (ABC, 2009).

Sobre internet, la fuente y el uso que tiene como herramienta para masificar los mensajes, Restrepo señala:

[...] internet en sí no es ni malo ni bueno: "Se encarga de potenciar lo bueno o lo malo que tiene el hombre”. Y agregó que el único control que tiene internet está en la conciencia de cada usuario” (ABC, 2009, 2). 
Es el usuario, los públicos, quienes tienen el libre albedrío de adoptar como cierta o no un mensaje o una noticia, bien sea en los medios tradicionales o en la red 2.0.

Otra vertiente ocurre cuando el medio, en sus intereses editoriales, distorsiona la verdad de lo expresado por la fuente; en efecto, aquí es importante hacer un llamado a mantener los principios éticos y, particularmente, deontológicos del periodismo. En ese orden, Lobos (2018) recogió un mensaje expresado por el papa Francisco, en el cual se exhorta a los profesionales de la comunicación a renovar el compromiso de informar con la verdad, verificar las fuentes y ser custodios de la comunicación.

Con respecto a las redes sociales como instrumentos usados para difundir noticias falsas ofake news, el papa opinó:

[...] estas falsas noticias cuentan con un potente elemento detonador: el uso manipulador de las redes sociales y de las lógicas que garantizan su funcionamiento. De modo que los contenidos, a pesar de carecer de fundamento, obtienen una visibilidad tal que incluso los desmentidos oficiales difícilmente consiguen contener los daños que producen.

(Lobos, 2018)

Informar con la verdad y poner, por encima de cualquier interés particular, el derecho de la colectividad a ser informada y no propagar informaciones falsas es un reto para el periodismo de hoy, pero, ¿qué debería ser la verdad para los medios? Lo ideal sería difundir hechos reales; sin embargo, el periodista, en su subjetividad o en el discurso ideológico del medio desde el cual informa, siempre agregará algún punto de vista propio o del mismo medio.

Lucas (2008) ratifica lo anterior al afirmar: 
[...] Cuando los medios de comunicación dicen defender la verdad en lo político, en lo económico y en lo social, muchas veces en realidad están defendiendo su verdad, que puede ser muy respetable, pero no es honesto ni veraz ni transparente presentarla como la única verdad.

(Lucas, 2008)

Otro aspecto para discutir en el mundo periodístico son las noticias o mensajes conocidos como posverdad. La Real Academia Española (2017) la define como "distorsión deliberada de una realidad, que manipula creencias y emociones con el fin de influir en la opinión pública y en actitudes sociales".

Amón (2016) agrega su propia definición de posverdad: “[...] Puede ser una mentira asumida como verdad o incluso una mentira asumida como mentira, pero reforzada como creencia o como hecho compartido en una sociedad" (Amón, 2016). Para este trabajo, la posverdad son verdades contadas a medias.

Pero, en un mundo global, con una alta presencia de las redes sociales como herramientas que propagan mensajes e informaciones, ciertas o falsas, o posverdades, de manera masiva, simultánea y de múltiples tendencias, ¿es posible que los medios se apeguen netamente a la verdad e informen adecuadamente a los públicos? Ese trabajo de insistir en que los medios sean responsables y digan la verdad será posible, en parte, siempre y cuando los usuarios de los medios insistan en un cambio, y traten de participar en la defensa de sus derechos como audiencia a recibir una información veraz y oportuna.

Existen tres mecanismos de autorregulación o de participación que puede intentar utilizar la ciudadanía en los medios: el ombudsman, las asociaciones de usuarios, otros colectivos similares y el consejo de prensa o de lectores (Aznar, 1999). 
El ombudsman es, según Aznar (1999), el defensor del lector, radioescucha o televidente. Su función principal es la de recibir las quejas de los usuarios relacionadas con erratas, información y otros contenidos (como la publicidad), y las de quienes se han visto afectados por informaciones. Sobre las asociaciones de usuarios y otros colectivos, Aznar (1999) destaca que se trata de movimientos que organizan a los ciudadanos para asumir una actitud crítica hacia los grandes medios como representantes del orden social tradicional.

En cuanto al consejo de prensa o de lectores, Canelón (2008) los define como "equipos de lectores y especialistas, constituidos en verdaderos directores editoriales, se reúnen semanalmente para opinar sobre el contenido de las secciones (qué se ha hecho bien y qué no tanto) y definir lo que debe hacerse en adelante" (p. 44).

Estas alternativas son viables y, si bien no son una garantía para cambiar la línea editorial de los medios, son un intento para demostrar el interés de las audiencias por recibir informaciones lo más apegadas a la verdad y basadas en valores.

\section{Agenda informativa y línea editorial}

La agenda en los medios de comunicación o la decisión de lo que es noticia la definen los jefes en forma consulta con los dueños del medio y encajada en una política editorial que, en aras de intereses económicos y políticos, define lo que el medio puede o no publicar.

La agenda informativa es planificada, una guía para el trabajo de recaudar datos, una orientación a la hora de divulgar información. En ocasiones la califican de subjetiva, de emitir informaciones que no son reales y hasta de silenciosa, por ocultar hechos a la opinión pública: 
Dada la persuasión e interpretación que existe desde el momento en que acontece el hecho y este llega al receptor, se podría decir que vivimos en una realidad subjetiva, una especie de matrix recargada que solo nos permite conocer representación de realidades y no la realidad misma. (Escobar, 2006)

En ocasiones, esa realidad y ese conocimiento del mundo y de la vida es producto de que "la agenda de los medios de información -agenda mediática - se convierte en la agenda pública, se transforma en opinión pública" (Rubio, 2009). El ciudadano común, en teoría, hablará sobre lo que ha visto o escuchado en los medios.

Rubio (2009) vincula la agenda mediática con la agenda setting de los investigadores McCombs y Shaw, quienes la definieron como un poder que tienen los medios para dirigir la atención de los públicos hacia ciertos temas y generar opinión pública.

Se trata entonces de una agenda mediática intencional, pero, chasta qué punto suele usarse hoy día? Ardèvol-Abreu (2015) asegura que, por ejemplo, en las llamadas crisis humanitarias solo se destaca, desde el punto de vista informativo, un aspecto de esta, el resto (potencialidades del país donde se producen u otros problemas de la población) no se menciona, se oculta, no es noticia.

Se trata de elementos que orientan la cobertura, el enfoque y la divulgación noticiosa, e irónicamente se cubre noticiosamente una situación particular de una región de la misma manera que en otros países aunque los problemas sean distintos entre ellos. Ese mismo criterio pareciera extenderse desde las redes sociales hacia los medios, que las toman en algunas ocasiones como base para pautar e instrumentar la agenda mediática. 
Los medios construyen agendas según su relación con el espacio público (Aruguete, 2017); son una especie de fuerzas decisorias en torno a lo que se publica y cómo se publica. Se entiende que esa relación mediática con los más o los menos poderosos determina inclusive la presentación de la noticia, en forma cuidadosa o no para evitar conflictividad entre el medio y el poder o mantener un equilibrio de cierta empatía con los menos poderosos.

En la agenda noticiosa, a juicio de Aruguete (2017) las circunstancias dramáticas y conflictivas abren, por así decirlo, un espacio a los más vulnerables. Se interpreta que solo en esas situaciones los no poderosos tienen una oportunidad mediática que, en el caso de los hechos de conmoción social o violentos en la sociedad, funciona para dar cuenta de hechos negativos con consecuencias, inclusive, fatales. Si vamos más allá, la presencia mediática de los sujetos vulnerables en la agenda funciona para informar sobre algo que les desfavorece e, inclusive, sobre sus desgracias.

También sobre la agenda setting se afirma que "[...] los medios de comunicación, sean cuales fueren, cumplen esa función simplificadora y orientadora sobre los temas a los que no accedemos de forma directa. Por ello, su función de transmisores es imprescindible” (Rodríguez, 2009, p. 440).

Se infiere que, en el caso de los temas de los cuales no se tienen noticias de manera directa o son desconocidos, el papel de los medios como intercesores de mensajes es fundamental, porque a través de ellos dichos temas se asumen y emergen en la opinión pública. Dicha opinión, en principio, estaría alienada a lo que pretenden los medios: lograr que los públicos y los temas estén vinculados a lo difundido. 
No obstante, Rodríguez (2009) afirma que el medio, por sí solo, no es un factor de influencia, sino que existen otros factores que pueden ser biológicos (personas) y hasta psicológicos en el proceso comunicacional. En su estudio sobre agenda setting aplicada al área educativa, demostró que, en la relación docente-estudiante, el profesor influye en la creación de una percepción positiva o negativa, pero siempre emergida desde el estudiantado. En el caso mediático, Rodríguez analiza qué factores, como la propia experiencia y el vínculo con familiares, amigos y hasta líderes de opinión, pueden ejercer influencia sobre la manera de ver y asumir los mensajes enviados por los medios. Por esto, los efectos de una agenda mediática no siempre podrían ser los esperados, sobre todo en las circunstancias actuales de globalización y redes sociales, que permiten dar o no testimonio de una realidad, cuya credibilidad está en las manos de las audiencias o usuarios.

\section{Pauta basada en las redes}

Actualmente, y gracias a las tecnologías, existe un acceso casi ilimitado a la información. La tecnología puso la información en manos de una diversidad de personas, que hace mucho tiempo se apropiaron de la comunicación y multiplican los mensajes en una sociedad global.

En la actualidad se habla de periodismo ciudadano. González y Soto (citados por González, 2012) afirman que el periodismo ciudadano emergió hace ya un tiempo, a partir de la masificación de los blogs. A partir de ese canal, diversos ciudadanos recogen datos, redactan y publican "noticias" en las redes.

Ya no se trata solo de periodistas o de personas reconocidas e influyentes en redes sociales; es el ciudadano común con sus dispositivos móviles que capturan los hechos y los replican a otros, en una cadena que llega hasta los medios de comunicación social. Sin embargo, queda de parte del medio 
utilizar o no el flujo de información que recorre las redes sociales, sobre todo porque se trata de mensajes que pueden ser falsos, tergiversados y que en definitiva, de publicarse, pondrían en tela de juicio la ética del medio.

Sobre la importancia de las redes y la información, Iglesias (2015) admite que las redes tienen el mismo valor como insumo informativo que los medios digitales y los tradicionales. Por esto, difundir información mediante ellas como agenda noticiosa es factible en un mundo en el cual los medios tradicionales no tienen la opción de quedarse atrás y correr el riesgo de no publicar informaciones conocidas por los usuarios de las tecnologías digitales y sobre todo por la empatía redes-ciudadanos. En cuanto a basarse en las redes para guiar el trabajo periodístico, un estudio sobre periodismo y redes sociales efectuado en Chile arrojó que los periodistas chilenos usan las redes sociales para la búsqueda, difusión y verificación de datos,y los profesionales de la TV son los que más las usan para buscar fuentes y corroborar información. Además, son utilizadas para saber qué está pasando principalmente cuando se trata de conflictos sociales, desastres o asuntos internacionales.

No obstante, "al mismo tiempo, la mayoría de los consultados cree que las redes influyen mucho en la pauta de los medios en general, pero menos en la del propio medio" (Valenzuela y Halpern, 2015, p. 34). Esto es una contradicción, porque justamente el periodista busca enterarse de hechos en tiempo real para utilizar la información como insumo por su medio o el de la competencia.

Por su parte, Cerviño (2013) considera que las redes sí marcan la agenda de los medios:

Este intercambio entre la agenda de los medios y la agenda pública confirma la hipótesis inicial de que los temas discutidos por el público en 
las redes sociales aportan contenido a los medios de comunicación, cambiando la relación de los periodistas con las fuentes de información.

(Cerviño, 2013, p. 79)

De acuerdo con lo anterior, en este artículo se comparte el punto de vista de Cerviño (2013). Hoy día las redes sociales forman parte del insumo para construir la agenda informativa, por lo que estamos en presencia de lo que aquí se denomina 'ciberagenda informativa', basada u originada desde los temas que se viralizan por los usuarios de las redes.

La ciberagenda monitorea y diagnostica en las redes lo que pudiera ser noticia; de allí, extrae los temas que a juicio del medio pueden de interés. Se trata de tópicos que serán pautados a los reporteros y formalizados como noticias desde el punto de vista periodístico, pero cuidando la política editorial del medio y abordando la temática sin perjudicar intereses pactados editorialmente.

La ciberagenda, al igual que la agenda tradicional, privilegiará los temas que giren en torno a lo que se consideran ganchos noticiosos: violencia, sexo, deporte y política. La única diferencia es que estos surgirán desde las comunidades virtuales, con base en hechos comprobables que hacen las veces de fuentes o replican lo sucedido, y alertando al campo periodístico sobre su importancia.

\section{Periodismo más allá de las redes}

Freitas (2016) considera indispensable que el manejo del periodismo digital esté en manos de profesionales formados para tal fin, e incluso va más allá en cuanto al abordaje de la comunicación digital. Para la autora, no todo lo que se publica en la web es comunicación digital, ya que los requisitos indispensables para que una divulgación sea considerada periodismo digital incluyen que tenga intención de informar y de construir audiencias, debe tener una estructura, ser novedosa y pertenecer a un 
género periodístico. Los más populares, como la noticia y el reportaje, requieren ser manejados por personas formadas en el oficio, no solo porque implica conocimientos básicos para la jerarquización y presentación de datos, sino por las consideraciones éticas.

Sobre ir más allá de las redes sociales y trabajar las redes periodísticamente, García et ál. (2014) refieren la posibilidad de hacer un trabajo más completo, que permita conocer los hechos de diversos géneros como crónicas o reportajes. Esto se traduce en que debe existir un compromiso por desarrollar los distintos géneros periodísticos en función de dar mayor cantidad posible de detalles a los usuarios, que solo han recibido un mensaje de pocos caracteres y que puede generar una matriz de opinión sin bases sólidas.

Igualmente, la necesidad de ampliar los mensajes provenientes de este tipo de plataforma debe considerar la brecha digital en los países. No todas las regiones tienen las mismas oportunidades de acceso; esto implica una desigualdad informativa que no favorece a las zonas donde son persistentes los conflictos internacionales.

A propósito, la ONU reconoce que, pese a los adelantos tecnológicos y el esfuerzo por algunas naciones por masificar el acceso a la plataforma digital,

[...] todavía persisten importantes brechas digitales, por ejemplo, entre países y dentro de ellos, y entre mujeres y hombres, que deben resolverse, entre otras cosas, fortaleciendo los entornos normativos y la cooperación internacional para mejorar la asequibilidad, el acceso, la educación, la creación de capacidad, el multilingüismo, la preservación cultural, la inversión y la financiación adecuada [...]. (ONU, 2017, p 6)

La brecha digital es una realidad así como el acceso no masivo a la información a través de internet y, en especial, mediante las redes sociales. 
Ya que siguen vigentes los medios de comunicación clásicos, particularmente la televisión, es importante que el periodismo tradicional continúe con su trabajo de indagar y mostrar lo más ampliamente posible las temáticas de interés a un gran sector de la población que todavía se informa por medios tradicionales, con el fin de que la noticia no se reduzca a la exclusividad de las redes sociales.

Al tema de la brecha digital se suman los aspectos éticos y de reconocimiento de la dignidad humana en las redes sociales, que pudieran estar afectando precisamente al sector de la población que no tiene posibilidades de acceso desde sus regiones por un tema económico de infraestructura, entre otros.

\section{Dignidad humana en tiempos sociodigitales}

En Venezuela, desde el punto de vista legal y deontológico, se protege la dignidad humana. En la Constitución de la República Bolivariana de Venezuela (2009), las premisas contenidas en los artículos 2, 3, 19 y 60 promulgan, entre distintos valores, la responsabilidad social, el goce y disfrute de los derechos humanos, la ética, la defensa y el desarrollo de la persona y el respeto a su dignidad. Asimismo, incluye el derecho a la protección del honor, vida privada, intimidad, propia imagen, confidencialidad y reputación.

Por otro lado, la Ley de Ejercicio del Periodismo (1995) insta a los comunicadores sociales a que en el ejercicio de la profesión actúen bajo “[...] principios de la ética profesional, al respeto y a la defensa de los derechos humanos, de la paz entre los pueblos, de la libertad de expresión al servicio de la verdad y la pluralidad de las informaciones" (art. 34, par. 1). Esto se extrapola hacia el buen trato de la persona, al ser sujeto de derechos y fuente o protagonista de los hechos reseñados. 
También el Código de Ética del Periodista Venezolano, en el artículo 5, refiere:

El periodista solo podrá informar, de la vida privada, aquello que sea de importancia para los intereses de la colectividad; está obligado a darles el tratamiento ajustado a la dignidad, la discreción y la veracidad que se merece la vida privada de cualquier ciudadano venezolano. (Consejo Nacional de Periodista [CNP], 2013, art. 5)

Asimismo, en los artículos 8 y 11 se encomienda a los periodistas evitar la divulgación de mensajes que denigren o humillen al ser o que vulneren la dignidad de las personas.

Por su parte, la Ley de Responsabilidad Social en Radio Televisión y Medios Electrónicos (Asamblea Nacional de la República Bolivariana de Venezuela, 2011, art. 27) prohíbe la difusión de mensajes que promuevan intolerancia u odio por, entre otros, racismo y xenofobia.

Esto significa que los medios tienen un compromiso con la dignidad del hombre. El respeto redunda en el desarrollo de los ciudadanos y de la sociedad. No respetar la dignidad es igual a propiciar el desconocimiento de lo humano, por encima de todas las cosas. También significa que se prefiere cosificar la condición del ser y convertirla en un valor de cambio. En esa misma línea, para A Favor de lo Mejor (2004), los medios, en algunos momentos, han de presentar el dolor o las pasiones humanas, pero la presentación debe evitar la crudeza, menos aún justificarlo o alentarlo. Se interpreta que los medios no deben autocensurarse y difundir las informaciones y mensajes como parte de su compromiso con la verdad. Esa difusión debe hacerse respetando el dolor ajeno, el respeto y la consideración hacia el otro.

En el caso de las redes sociales, tratar de crear conciencia sobre lo que debe o no divulgarse y si esa divulgación compromete la dignidad humana 
y los valores éticos en materia de comunicación y derechos humanos es un dilema. Se trata de redes libres y manejadas por una diversidad de individuos no necesariamente comprometidos con la ética.

Esto se vivió con el video en la red de la ejecución de Sadan Husein y con mayor intensidad en el 2011 con la llamada Primavera Árabe. La experiencia en video sobre la sodomización y asesinato de Muamar el Gadafi recorrió las redes sociales, para entonces incipientes en el mundo árabe, sin importar la condición humana de la víctima y los sentimientos de sus familiares y allegados. Más recientemente, se divulgaron las decapitaciones de rehenes ejecutadas por el Estado Islámico y que también han circulado libremente en la red.

Aunque es difícil limitar a la red de redes, es trabajo de los medios con presencia en la red y con un amplio número de seguidores extrapolar los principios éticos periodísticos y de derechos humanos, en los mensajes que tengan como fuente primaria las redes sociales.

Korin (2011) fija posición al mencionar que los medios de comunicación social son considerados empresas con responsabilidades y exigencias éticas a instrumentar. Los medios tienen que medir el impacto de sus acciones y hacerse responsables de ellas, aunque "[...] a los medios no se les suele exigir tanto en materia de responsabilidad como a empresas de otros sectores" (Korin, 2011, p. 193).

Esa "poca" exigencia se debe a la naturaleza de los medios, que si bien son estructuralmente empresas y tiene un fin rentable, cumplen una función social como lo es la difusión de informaciones. Esto implica que su responsabilidad está dirigida a la transmisión de mensajes que no produzcan daño a los usuarios y, de hacerlo, el medio debe responder por ello. 
La empresa de medios de comunicación está conformada por humanos y trata con humanos; de allí que la relación no debería ser mecánica, sino orientada hacia el bienestar del común de los usuarios con quienes mantienen relaciones.

Ahora bien, la responsabilidad es vista como "[...] la capacidad de responder por lo que se hace o se deja de hacer, así como por las correspondientes consecuencias que proceden de lo que se hizo o no se hizo" (Guedez, 2006, p. 86). Comprende una serie de aspectos como el de la difusión de mensajes acordes con los intereses de los usuarios; si estos, no son de su interés y ocasionan algún menoscabo en cuanto su integridad como persona, el medio debería aceptar su falta y proceder a la corrección. La gran diferencia entre la clásica responsabilidad social empresarial y la responsabilidad ética empresarial es que mientras en la primera su fin es la filantropía (las acciones sociales en el plano de las colaboraciones, donativos, trabajo voluntario, entre otros), la segunda implica dar respuestas cuando las acciones acarrean consecuencias generadoras de conflictos. Se pretende que los medios de comunicación social, como empresas, asuman una responsabilidad ética, que sean responsables ante los usuarios por lo que divulgan.

\section{Realidad venezolana medios y redes}

El trabajo consistió en analizar los dos principales diarios del país: $E l$ Nacional y El Universal, por su trayectoria, tiraje y por ser medios de circulación nacional con mayor penetración en su versión impresa y contar con versión digital y presencia en redes sociales.

A través de una ficha de precisión se analizaron los medios en su versión digital, antes mencionados, porque tienen la cultura 2.0 de actualizar durante el día las informaciones en su plataforma. El análisis se basó en la 
aplicación de la ficha a 7 hechos con víctimas fatales, relacionadas a las protestas en Venezuela, durante el periodo abril-junio de 2017 y que tuvieron presencia divulgativa tanto en las redes sociales como en los medios tradicionales. Estos sucesos escogidos de manera aleatoria son los siguientes fallecimientos: Carlos José Moreno Barón, Paola Andreína Ramírez Gómez, Juan Pablo Pernalete Llovera, Armando Cañizales Carrillo, Paul Moreno, Neomar Lander y David Vallenilla.

En la ficha de precisión se abordaron tópicos: medio, los hechos (lo sucedido), titulares, red social fuente (la cual sirvió como fuente indirecta al medio para indagar sobre la noticia), género periodístico desarrollado por el medio con base en los mensajes de las redes sociales, así como imágenes divulgadas. En este último caso se hizo una síntesis descriptiva de lo divulgado por el medio en relación con el tema de investigación, con e fin de tener una representación gráfica de los hechos difundidos bien sea a modo de fotografía o video y usando como herramientas las redes sociales.

Igualmente la ficha incluyó las fuentes directas (primaria viva o personas con capacidad de aportar datos y testimonios) consultadas por el medio, para reseñar los hechos y brindar a los lectores más información sobre las noticias puestas a la luz pública. El análisis, por cada caso, fue el siguiente: Carlos José Moreno Barón. Este joven de 17 años cursaba el primer semestre de Economía en la Universidad Central de Venezuela (UCV); murió el 19 de abril, durante una protesta de la oposición en la plaza La Estrella de San Bernardino, Caracas. El día del suceso el diario El Nacional tituló: “Asesinaron a joven en concentración opositora en San Bernardino"; usó como fuente Twitter, desarrolló una noticia y citó siete tuits, acompañó la nota con una imagen del hecho en la cual se observa a la víctima en el suelo con el rostro y rastro de sangre difuminado; 
igualmente el diario complementó la información con entrevistas realizadas al periodista Víctor Amaya y a la diputada Olivia Lozano.

El diario El Universal tituló: "Muere joven herido en manifestación opositora en la plaza La Estrella”; usó como red social fuente el Twitter y desarrolló una noticia y en el pie de nota se cita un tuit que hace referencia a una segunda víctima, en la foto de la nota la víctima no se ve porque es tapada por una persona que aparece en primer plano. No se consultó fuente primaria (tabla 1).

Tabla 1. Protestas 2017 en Venezuela redes y medios de comunicación. Carlos Moreno

\begin{tabular}{|c|c|c|c|c|c|c|}
\hline Medio & Hechos & Título & $\begin{array}{c}\text { Red } \\
\text { social } \\
\text { fuente }\end{array}$ & $\begin{array}{c}\text { Género } \\
\text { periodístico } \\
\text { desarrollado }\end{array}$ & $\begin{array}{l}\text { Imagen } \\
\text { divulgada }\end{array}$ & $\begin{array}{l}\text { Fuente } \\
\text { directa }\end{array}$ \\
\hline $\begin{array}{l}\text { El } \\
\text { Nacional }\end{array}$ & $\begin{array}{l}\text { Muerte } \\
\text { de } \\
\text { Carlos } \\
\text { Moreno }\end{array}$ & $\begin{array}{l}\text { "Asesinaron a } \\
\text { joven en } \\
\text { concentración } \\
\text { opositora en } \\
\text { San } \\
\text { Bernardino" }\end{array}$ & Twitter & $\begin{array}{l}\text { Noticia y en el } \\
\text { pie de nota se } \\
\text { citan siete } \\
\text { tuits }\end{array}$ & $\begin{array}{l}\text { Foto del } \\
\text { hecho. La } \\
\text { víctima en } \\
\text { el suelo } \\
\text { con el } \\
\text { rostro y } \\
\text { rastro de } \\
\text { sangre } \\
\text { difuminado }\end{array}$ & $\begin{array}{l}\text { Periodista } \\
\text { Víctor } \\
\text { Amaya } \\
\text { Diputada } \\
\text { Olivia } \\
\text { Lozano }\end{array}$ \\
\hline $\begin{array}{l}\text { El } \\
\text { Universal }\end{array}$ & $\begin{array}{l}\text { Muerte } \\
\text { de } \\
\text { Carlos } \\
\text { Moreno }\end{array}$ & $\begin{array}{l}\text { "Muere joven } \\
\text { herido en } \\
\text { manifestación } \\
\text { opositora en la } \\
\text { plaza La } \\
\text { Estrella" }\end{array}$ & Twitter & $\begin{array}{l}\text { Noticia y en el } \\
\text { pie de nota se } \\
\text { cita un tuits } \\
\text { que hace } \\
\text { referencia a } \\
\text { una segunda } \\
\text { víctima. }\end{array}$ & $\begin{array}{l}\text { Foto del } \\
\text { hecho. La } \\
\text { víctima no } \\
\text { se ve } \\
\text { porque es } \\
\text { tapada por } \\
\text { una } \\
\text { persona } \\
\text { que } \\
\text { aparece en } \\
\text { primer } \\
\text { plano. }\end{array}$ & \\
\hline
\end{tabular}

Fuente: elaboración propia.

Paola Ramírez, de 23 años, murió en una manifestación opositora cerca de la plaza San Carlos (también conocida como plaza de las palomas) en San Cristóbal, estado Táchira, el 19 de abril. El Nacional lo tituló: “Asesinaron a mujer de 23 años durante protesta en Táchira”, la red social utilizada 
como fuente es Twitter; desarrolló una noticia y al final de la nota se agregaron dos tuits. En cuanto a la imagen utilizada, en una primera foto aparece el cuerpo de la víctima cubierto con una sábana. En una segunda foto se observa su cédula de identidad. Fuente directa: vecinos del sector San Carlos de Barrio Obrero.

El Universal tituló: "Falleció una joven por disparo en marcha opositora en el estado Táchira”, la red social fuente es Twitter. Se desarrolló la noticia con una imagen que reproduce la cédula de identidad de la víctima y se citan dos tuits; además, usa como fuente directa: vecinos del lugar (tabla 2).

Tabla 2. Protestas 2017 en Venezuela redes y medios de comunicación. Paola Ramírez

\begin{tabular}{|c|c|c|c|c|c|c|}
\hline Medio & Hechos & Título & $\begin{array}{l}\text { Red } \\
\text { social } \\
\text { fuente }\end{array}$ & $\begin{array}{c}\text { Género } \\
\text { periodístico } \\
\text { desarrollado }\end{array}$ & $\begin{array}{l}\text { Imagen } \\
\text { divulgada }\end{array}$ & $\begin{array}{l}\text { Fuente } \\
\text { directa }\end{array}$ \\
\hline $\begin{array}{l}\text { El } \\
\text { Nacional }\end{array}$ & $\begin{array}{l}\text { Muerte } \\
\text { Paola } \\
\text { Ramírez }\end{array}$ & $\begin{array}{l}\text { Asesinaron } \\
\text { a mujer de } \\
23 \text { años } \\
\text { durante } \\
\text { protesta en } \\
\text { Táchira }\end{array}$ & Twitter & $\begin{array}{l}\text { Noticia y cita dos } \\
\text { tuits. }\end{array}$ & $\begin{array}{l}\text { Una primera } \\
\text { foto aparece el } \\
\text { cuerpo de la } \\
\text { víctima } \\
\text { cubierto con } \\
\text { una sábana. } \\
\text { Segunda foto } \\
\text { reproduce su } \\
\text { cédula de } \\
\text { identidad o } \\
\text { identificación } \\
\text { de la víctima. }\end{array}$ & $\begin{array}{l}\text { Vecinos } \\
\text { del } \\
\text { sector } \\
\text { San } \\
\text { Carlos } \\
\text { de } \\
\text { Barrio } \\
\text { Obrero }\end{array}$ \\
\hline $\begin{array}{l}\text { El } \\
\text { Universal }\end{array}$ & $\begin{array}{l}\text { Muerte } \\
\text { Paola } \\
\text { Ramírez }\end{array}$ & $\begin{array}{l}\text { Falleció } \\
\text { una joven } \\
\text { por disparo } \\
\text { en marcha } \\
\text { opositora } \\
\text { en el estado } \\
\text { Táchira }\end{array}$ & Twitter & Noticia & $\begin{array}{l}\text { Reproducción } \\
\text { cédula de } \\
\text { identidad o } \\
\text { identificación } \\
\text { de la víctima. }\end{array}$ & $\begin{array}{l}\text { Vecinos } \\
\text { del } \\
\text { lugar }\end{array}$ \\
\hline
\end{tabular}

Fuente: elaboración propia.

Juan Pernalete, de 20 años, estudiante de Economía en la Universidad Metropolitana, murió el 26 de abril durante una protesta de oposición en Altamira, estado Miranda. El Nacional tituló: “Difunden video con últimos 
segundos de vida de Juan Pablo Pernalete”. Se utilizó como red social fuente Instagram (cuenta del periodista Marcos Morin); se desarrolló una noticia acompañada de una foto en vida del joven, un tuit y video en el cual se observa a los manifestantes cuando cargan al joven y luego cae al suelo. No fueron consultadas fuentes primarias.

El Universal tituló: "Reportan muerte de joven de 20 años en Altamira”; red social fuente: Twitter. Género periodístico: noticia con un tuit al final de la nota e imagen de los familiares a las afueras de centro asistencial. Fuente primaria: no consultada (tabla 3).

Tabla 3. Protestas 2017 en Venezuela redes y medios de comunicación. Juan Pernalete

\begin{tabular}{|c|c|c|c|c|c|c|}
\hline Medio & Hechos & Título & $\begin{array}{c}\text { Red } \\
\text { social } \\
\text { fuente }\end{array}$ & $\begin{array}{c}\text { Género } \\
\text { periodístico } \\
\text { desarrollado }\end{array}$ & $\begin{array}{c}\text { Imagen } \\
\text { divulgada }\end{array}$ & $\begin{array}{l}\text { Fuente } \\
\text { directa }\end{array}$ \\
\hline $\begin{array}{l}\text { El } \\
\text { Nacional }\end{array}$ & $\begin{array}{l}\text { Muerte } \\
\text { Juan } \\
\text { Pernalete }\end{array}$ & $\begin{array}{l}\text { "Difunden } \\
\text { video con } \\
\text { últimos } \\
\text { segundos } \\
\text { de vida de } \\
\text { Juan Pablo } \\
\text { Pernalete" }\end{array}$ & Instagram & Noticia & $\begin{array}{l}\text { Foto en vida } \\
\text { del joven y } \\
\text { Video } \\
\text { manifestantes } \\
\text { cargan al joven } \\
\text { y luego cae al } \\
\text { suelo. }\end{array}$ & \\
\hline $\begin{array}{l}\text { El } \\
\text { Universal }\end{array}$ & $\begin{array}{l}\text { Muerte } \\
\text { de Juan } \\
\text { Pernalete }\end{array}$ & $\begin{array}{l}\text { "Reportan } \\
\text { muerte de } \\
\text { joven de } \\
20 \text { años en } \\
\text { Altamira" }\end{array}$ & Twitter & Noticia & $\begin{array}{l}\text { Foto de } \\
\text { familiares a las } \\
\text { afuera de } \\
\text { centro de } \\
\text { salud. }\end{array}$ & \\
\hline
\end{tabular}

Fuente: elaboración propia.

Armando Cañizales, músico de 17 años, murió el 3 de mayo durante una protesta en Las Mercedes, municipio Baruta del estado Miranda. El Nacional tituló: "Revelan los últimos minutos de vida de Armando Cañizales". La red social fuente fue un medio digital (Caraota Digital), donde se desarrolló una noticia con una foto en vida del joven y un video. Fuente directa: no consultada. El Universal tituló: "Falleció joven de 17 años durante protestas en Caracas"; la red social fuente fue Twitter. Se 
desarrolló una noticia con foto de una manifestación en primer plano pelotón de la Guardia Nacional. Fuente directa: no evidenciada (tabla 4).

Tabla 4. Protestas 2017 en Venezuela redes y medios de comunicación. Armando Cañizales

\begin{tabular}{|c|c|c|c|c|c|c|}
\hline Medio & Hechos & Título & $\begin{array}{c}\text { Red } \\
\text { social } \\
\text { fuente }\end{array}$ & $\begin{array}{c}\text { Género } \\
\text { periodístico } \\
\text { desarrollado }\end{array}$ & $\begin{array}{c}\text { Imagen } \\
\text { divulgada }\end{array}$ & $\begin{array}{l}\text { Fuente } \\
\text { directa }\end{array}$ \\
\hline $\begin{array}{l}\text { El } \\
\text { Nacional }\end{array}$ & $\begin{array}{l}\text { Muerte } \\
\text { Armando } \\
\text { Cañizales }\end{array}$ & $\begin{array}{l}\text { "Revelan } \\
\text { los } \\
\text { últimos } \\
\text { minutos } \\
\text { de vida de } \\
\text { Armando } \\
\text { Cañizales" }\end{array}$ & $\begin{array}{l}\text { Web } \\
\text { medio } \\
\text { digital }\end{array}$ & Noticia & $\begin{array}{l}\text { Foto en vida } \\
\text { del joven }\end{array}$ & \\
\hline $\begin{array}{l}\text { El } \\
\text { Universal }\end{array}$ & $\begin{array}{l}\text { Muerte de } \\
\text { Armando } \\
\text { Cañizales }\end{array}$ & $\begin{array}{l}\text { "Falleció } \\
\text { joven de } \\
17 \text { años } \\
\text { durante } \\
\text { protestas } \\
\text { en } \\
\text { Caracas" }\end{array}$ & Twitter & Noticia & $\begin{array}{l}\text { Foto de una } \\
\text { manifestación } \\
\text { en primer } \\
\text { plano pelotón } \\
\text { de la Guardia } \\
\text { Nacional. }\end{array}$ & \\
\hline
\end{tabular}

Fuente: elaboración propia.

Paul Moreno, de 24 años, miembro de los cascos blancos de la Cruz Verde Maracaibo y estudiante de Medicina en Universidad del Zulia, murió el 18 de mayo durante una protesta en la Av. Fuerzas Armadas de Maracaibo, estado de Zulia. El Nacional tituló: "Asesinaron a miembro de la Cruz Verde durante protesta en Maracaibo"; la red social fuente es Twitter y se abordó en forma de noticia con una foto del sitio donde ocurrió el hecho, no se visualiza a la víctima. Fuente directa: Daniela Guerra, abogada. $E l$ Universal tituló: "Fallece estudiante de medicina al ser arrollado en protesta en Maracaibo". La red social fuente fue Twitter; se desarrolló una noticia con foto de la víctima en vida. Fuente primaria: no observada (tabla 5).

Neomar Lander, estudiante de 17 años, murió el 7 de junio durante una protesta opositora en la Av. Libertador de Caracas. El Nacional tituló: "Video exclusivo del momento preciso en que cayó Neomar Lander", la red 
social fuente fue el canal de internet; se desarrolló una noticia acompañada de video del hecho que arrojó como saldo la víctima, firmado por el diario. La fuente directa fue el alcalde de municipio Chacao Ramón Muchacho. El Universal tituló: "Muere adolescente de 17 años durante manifestación en Chacao"; la red social fuente fue un canal de internet. Se desarrolló una noticia y en el pie de página se citan varios tuits acompañados de video con la víctima ensangrentada. Fuente directa: no consultada (tabla 6). 
Tabla 5. Protestas 2017 en Venezuela redes y medios de comunicación. Paul Moreno

\begin{tabular}{|c|c|c|c|c|c|c|}
\hline Medio & Hechos & Título & $\begin{array}{l}\text { Red social } \\
\text { fuente }\end{array}$ & $\begin{array}{l}\text { Género periodístico } \\
\text { desarrollado }\end{array}$ & $\begin{array}{l}\text { Imagen } \\
\text { divulgada }\end{array}$ & $\begin{array}{l}\text { Fuente } \\
\text { directa }\end{array}$ \\
\hline El Nacional & $\begin{array}{l}\text { Muerte de Paul } \\
\text { Moreno }\end{array}$ & $\begin{array}{l}\text { "Asesinaron a } \\
\text { miembro de la Cruz } \\
\text { Verde durante } \\
\text { protesta en } \\
\text { Maracaibo" }\end{array}$ & Twitter & Noticia & $\begin{array}{l}\text { Foto: del sitio } \\
\text { donde ocurrió el } \\
\text { hecho no se } \\
\text { visualiza a la } \\
\text { víctima. }\end{array}$ & $\begin{array}{l}\text { Daniela } \\
\text { Guerra, } \\
\text { abogada }\end{array}$ \\
\hline El Universal & $\begin{array}{l}\text { Muerte de Paul } \\
\text { Moreno }\end{array}$ & $\begin{array}{l}\text { "Fallece estudiante } \\
\text { de medicina al ser } \\
\text { arrollado en } \\
\text { protesta en } \\
\text { Maracaibo" }\end{array}$ & Twitter & Noticia & $\begin{array}{l}\text { Foto en vida de la } \\
\text { víctima }\end{array}$ & \\
\hline
\end{tabular}

Fuente: elaboración propia.

Tabla 6. Protestas 2017 en Venezuela redes y medios de comunicación. Neomar Lander

\begin{tabular}{|c|c|c|c|c|c|c|}
\hline Medio & Hechos & Título & $\begin{array}{l}\text { Red social } \\
\text { fuente }\end{array}$ & $\begin{array}{c}\text { Género } \\
\text { periodístico } \\
\text { desarrollado }\end{array}$ & Imagen divulgada & $\begin{array}{l}\text { Fuente } \\
\text { directa }\end{array}$ \\
\hline El Nacional & $\begin{array}{l}\text { Muerte de } \\
\text { Neomar } \\
\text { Lander }\end{array}$ & $\begin{array}{l}\text { "Video exclusivo del } \\
\text { momento preciso en } \\
\text { que cayó Neomar } \\
\text { Lander" }\end{array}$ & $\begin{array}{l}\text { Canal de } \\
\text { Internet del } \\
\text { diario }\end{array}$ & Noticia & $\begin{array}{l}\text { Video del hecho que } \\
\text { arrojó como saldo la } \\
\text { víctima }\end{array}$ & $\begin{array}{l}\text { Alcalde de } \\
\text { Municipio } \\
\text { Chacao Ramón } \\
\text { Muchacho }\end{array}$ \\
\hline El Universal & $\begin{array}{l}\text { Muerte de } \\
\text { Neomar } \\
\text { Lander }\end{array}$ & $\begin{array}{l}\text { "Muere adolescente } \\
\text { de } 17 \text { años durante } \\
\text { manifestación en } \\
\text { Chacao" }\end{array}$ & $\begin{array}{l}\text { Canal de } \\
\text { internet }\end{array}$ & $\begin{array}{l}\text { Noticia y en el pie de } \\
\text { página se citan varios } \\
\text { tuits }\end{array}$ & $\begin{array}{l}\text { Video con la víctima } \\
\text { ensangrentada. }\end{array}$ & \\
\hline
\end{tabular}

Fuente: elaboración propia. 
David Vallenilla, estudiante de enfermería de 22 años, murió el 22 de junio en la autopista Francisco Fajardo en una protesta cerca de la base militar La Carlota. El Nacional tituló: "El momento exacto en que un sargento le disparó a David Vallenilla"; la red social fuente fue canal Internet. Se desarrolló una noticia con relevancia de imágenes y video disponible e imágenes extraídas del video del momento en que ocurrió el hecho. Fuente directa: diputado José Manuel Olivares. El Universal tituló: "Asesinan a joven de 22 años en protesta frente a La Carlota"; la red social fuente fue el canal internet. Se desarrolló una noticia con imagen del momento en el cual ocurrió el hecho y extraída de un video colgado en la red. Fuente directa: no observada (tabla 7).

Tabla 7. Protestas 2017 en Venezuela redes y medios de comunicación. David Vallenilla

\begin{tabular}{|c|c|c|c|c|c|c|}
\hline Medio & Hechos & Título & $\begin{array}{c}\text { Red } \\
\text { social } \\
\text { fuente }\end{array}$ & $\begin{array}{c}\text { Género } \\
\text { periodístico } \\
\text { desarrollado }\end{array}$ & $\begin{array}{l}\text { Imagen } \\
\text { divulgada }\end{array}$ & $\begin{array}{l}\text { Fuente } \\
\text { directa }\end{array}$ \\
\hline $\begin{array}{l}\text { El } \\
\text { Nacional }\end{array}$ & $\begin{array}{l}\text { Muerte } \\
\text { de David } \\
\text { Vallenilla }\end{array}$ & $\begin{array}{l}\text { "El } \\
\text { momento } \\
\text { exacto en } \\
\text { que un } \\
\text { sargento } \\
\text { le disparó } \\
\text { a David } \\
\text { Vallenilla" }\end{array}$ & $\begin{array}{l}\text { Canal } \\
\text { de } \\
\text { Internet } \\
\text { del } \\
\text { diario }\end{array}$ & $\begin{array}{l}\text { Noticia con } \\
\text { relevancia de } \\
\text { imágenes }\end{array}$ & $\begin{array}{l}\text { Video e } \\
\text { imágenes } \\
\text { extraídas } \\
\text { del video } \\
\text { del } \\
\text { momento } \\
\text { en que } \\
\text { ocurrió el } \\
\text { hecho }\end{array}$ & $\begin{array}{l}\text { Diputado } \\
\text { José } \\
\text { Manuel } \\
\text { Olivares }\end{array}$ \\
\hline $\begin{array}{l}\text { El } \\
\text { Universal }\end{array}$ & $\begin{array}{l}\text { Muerte } \\
\text { de David } \\
\text { Vallenilla }\end{array}$ & $\begin{array}{l}\text { "Asesinan } \\
\text { a joven de } \\
22 \text { años } \\
\text { en } \\
\text { protesta } \\
\text { frente a } \\
\text { La } \\
\text { Carlota” }\end{array}$ & $\begin{array}{l}\text { Canal } \\
\text { de } \\
\text { Internet }\end{array}$ & Noticia & $\begin{array}{l}\text { Foto } \\
\text { extraída de } \\
\text { video y en } \\
\text { el cual se } \\
\text { aprecia el } \\
\text { momento } \\
\text { en que } \\
\text { ocurre el } \\
\text { hecho. }\end{array}$ & \\
\hline
\end{tabular}

Fuente: elaboración propia. 


\section{Análisis de los resultados}

En los siete hechos citados hubo intención de parte de los medios analizados en cumplir con el protocolo de buscar la información, complementar las fuentes y desarrollar noticias. Sin embargo, se notó que la mayoría de las imágenes que acompañan a los géneros periodísticos desarrollados, no son generadas por el medio, sino que forman parte del grupo de fotos y videos divulgados en las redes sociales para el momento de los hechos.

En los diarios estudiados, en algunos casos, el título invita a los usuarios a ver el video de cómo ocurrió el lamentable saldo fatal, como fue en los casos de las víctimas Neomar Lander, David Vallenilla y Juan Pernalete. Sin embargo, por ser medios con un buen nivel de penetración, pueden ser vistos por una diversidad de ciberlectores y los videos no son aptos para todo público, lo que puede generar un impacto a quienes accedan a ellos. Este tipo de medios hace caso omiso a las leyes y códigos deontológicos existentes en el país, en cuanto evitar la emisión de mensajes que vulneren valores, expongan al escarnio público provoquen sentimientos afecta que al ser y dignidad.

Tanto El Nacional como El Universal se mantienen en la clásica gestión de medios que busca acaparar la atención de los públicos, usando como gancho los llamados sucesos o páginas rojas para mostrar a través de un video cómo ocurrió un hecho y su lamentable desenlace. Es una estrategia editorial para ganar seguidores desde la perspectiva de la violencia mediática, en este caso en la plataforma digital que tiene una positiva penetración en los públicos jóvenes y adultos contemporáneos. Como lamentablemente esas protestas generaron víctimas fatales, sobresaltar ese tipo de sucesos estuvo por encima de cualquier equilibrio 
informativo, de modo que se pensó más en el medio y su línea editorial que en los usuarios y los familiares de las víctimas.

Abad (2010) explica que los medios operan como autores y cómplices en la divulgación de antivalores que vulneran los derechos humanos:

[...] venden como noticia su evangelio de violencia y desgracia cotidiana; comercializan huracanes, terremotos, sequías, balaceras, traiciones, corrupción y terrorismo mediático depurado como producción de espejismos, ante las miradas atónitas de la población [...]. (Abad, 2010, p. 127)

Para la divulgación de los mensajes no importa el qué (la información) sino el cómo se va a "presentar" la novedad. Martín Barbero (1998) comparte este punto de vista y analiza que la información, su proceso de elaboración, es lo más parecido a un reality show, un espectáculo en el cual lo menos importante es la investigación, el análisis y la argumentación sino su teatralidad o el sensacionalismo.

Igualmente las protestas estuvieron presentes en la agenda de los medios. Estos se encargaron de mantener a los públicos en los hechos asociados, en primer lugar, porque las manifestaciones eran en contra del Gobierno y, en segundo lugar, porque como consecuencia de cada evento, había ciudadanos afectados o pérdidas fatales. El estudio denotó que ambos medios, en algunas ocasiones, publicaron las mismas imágenes sobre las pérdidas humanas, como la víctima Paola Ramírez los dos medios reprodujeron como imagen su cédula de identidad; en los casos de Neomar Lander y David Vallenilla tanto El Nacional y El Universal insertaron el mismo video que evidencia cómo se desarrollaron los hechos fatales. Estos dos diarios compartieron sobre qué cubrir (la agenda del día) y el cómo hacerlo (cobertura y forma de divulgar): todo ello para asegurar matrices de opinión y mantener el tema en la palestra, lo que ratifica así 
las palabras de Rubio (2009) en torno a que "la agenda de los medios de información -agenda mediática - se convierte en la agenda pública, se transforma en opinión pública" (Rubio, 2009, p. 2).

En algunos casos se resaltó el hecho violento y sus consecuencias: la muerte. Estos medios semejaron las protestas venezolanos a las situaciones de crisis humanitarias ocurridas en otras latitudes y por ello se apegaron a lo destacado por Ardèvol-Abreu (2015) al incluir el tema en la agenda mediática y aspectos como: impacto humano (llegar a los cibernautas, alterar sensaciones), intereses nacionales (en este caso sería intereses trasnacionales o de grupos contrarios al Gobierno), proximidad psicológica (buena parte de los fallecidos son jóvenes), importancia estratégica (desde el punto de vista político-económico), interés del público, novedad, accesibilidad y coste del material informativo, producción propia elaboración de algún género periodístico, originalidad y coherencia con la personalidad e ideología del periódico (los medios estudiados son de oposición y por ende defienden sus intereses).

Sobre el uso de las redes sociales como fuentes, en los siete casos se evidenció que los medios usaron como fuente, para conocer de los hechos, Twitter, a excepción del caso Juan Pernalete, del cual El Nacional usó en la red Instagram. En algunas noticias son citados algunos tuits como en las notas de la muerte de Carlos Moreno publicada por El Nacional y El Universal e igualmente en la nota de Neomar Lander publicada por $E l$ Universal. Esto respalda lo que afirma Cerviño (2013): “[...] Los temas y contenidos tratados en las redes sociales influyen en la construcción de la noticia, de manera que las redes ejercen una innegable influencia en el establecimiento del agenda-setting de los medios" (Cerviño, 2013, p. 79). Twitter sí influyó en El Nacional y El Universal para elaborar la agenda mediática, como arrojó el estudio de Valenzuela y Halpern sobre “[...] que 
las redes influyen mucho en la pauta de los medios en general [...]” (Valenzuela y Halpern, 2015, p. 34).

Medios como El Nacional fueron más allá de las redes y sus periodistas para complementar los mensajes recibidos consultaron fuentes oficiales e incluso de familiares y amigos de las víctimas para desarrollar el género noticia en algunos de los casos de estudio (Carlos Moreno, Paola Ramírez, Paul Moreno, Neomar Lander y David Vallenilla). Este aspecto va en consonancia con Freitas (2016) quien considera indispensable que el manejo del periodismo digital esté en manos de profesionales formados para tal fin, e incluso va más allá en cuanto al abordaje de la comunicación digital; al decir que no todo lo que se publica en la web es comunicación digital, por lo que necesita tratamiento de los profesionales de la comunicación.

Como el estudio solo se basó en el análisis de la nota divulgada por los medios el mismo día del suceso, no se observó el desarrollo de géneros periodísticos como la entrevista o el reportaje que permiten ahondar en los hechos y aprovechar lo que llega a través de la tecnología y es descrito por García et ál. (2014) como "[...] una materia prima con la que es posible elaborar productos de mayor complejidad, con un valor añadido, gracias a la convergencia entre medios y tecnología”.

Con respecto al valor dignidad humana en la divulgación de los mensajes digitales por parte de los medios estudiados y basados en la conceptualización aportada por A Favor de lo Mejor (2010), sobre la presentación del dolor por parte de los medios, pero evitando la crudeza; se interpreta que los diarios, en algunos casos, irrespetaron a las víctimas y a sus familiares, al mostrar imágenes (fotos/videos) que reflejaron el estado maltrecho de estos ciudadanos en estado crítico o ya fallecido sin importar a quien llegan esas imágenes. Tenemos en el caso 
de Carlos Moreno El Nacional, aunque difuminó la foto igual se denota un cuerpo y sangre alrededor, lo que impacta a quien la observe; por su parte, El Universal tapa a la víctima colocando a una persona en primer plano, para evitar la imagen impactante.

Con Paola Ramírez, ambos diarios son más cautelosos y usan imágenes con el cuerpo cubierto y la reproducción de su cédula de identidad, lo que sugiere un mayor respeto de esta manera a la propia víctima, sus familiares y hasta el mismo ciberlector. El trato dado a Juan Pernalete por El Nacional aunque publicó en vida su foto, igualmente colgó el video de cómo transcurrieron los hechos, que muestra la agonía de la víctima por lo que hubo irrespeto y un trato inhumano; El Universal publicó una foto de los familiares fuera del centro asistencial, impregnando dramatismo al hecho.

Con Armando Cañizales y Paul Moreno tanto El Nacional como El Universal estuvieron a la altura, pues sus imágenes no muestran ápice de violencia, ni ilustran la fatalidad, lo que demuestra respeto. En el caso de Neomar Lander y David Vallenilla ambos medios usaron videos mostrando los hechos que resultaron en las víctimas fatales al igual que fotos relacionadas, lo que configura irrespeto y no considera la dignidad de los fallecidos y sus familiares.

En algunos casos, las actitudes de estos medios se alejan de la visión de Zenit (2004) al mencionar que los obispos del continente americano hacen un llamado para que la dignidad humana y la verdad orienten la labor de los medios de comunicación; porque su misión es la de contribuir al desarrollo del hombre y la sociedad.

Aunque se comprende lo afirmado por A Favor de lo Mejor (2004) sobre que los medios en algunos momentos han de presentar el dolor o las 
pasiones humanas, pero la presentación debe evitar la crudeza, menos aún justificarlo o alentarlo.

Igualmente se debe destacar que, de las 7 víctimas, tres eran menores de 18 años: Carlos Moreno, Armando Cañizales y Neomar Lander, por lo que en estos casos la forma de gestionar periodísticamente el suceso, debió tomar un rumbo distinto, al preservar incluso sus identidades y sus rostros ante la opinión pública. Se trata, en definitiva, de adolescentes recién salidos de la niñez y así debió recordárseles eternamente, jugando, sonriendo y no ensangrentados víctimas de la violencia de la calle y de la violencia mediática.

\section{Conclusiones}

Las redes sociales impusieron la agenda noticiosa durante las protestas en Venezuela del 2017. Los medios se basaron en ellas para la cobertura y desarrollo de informaciones, sobre todo las relacionadas a víctimas fatales. Se denota en algunas noticias divulgadas como se citó algunos tuits y colgaron fotos y videos que habían circulado en las redes.

Los medios estudiados consultaron fuentes diversas para complementar la información; en ese sentido, se impuso el periodismo como especialidad. Los mensajes o datos considerados de interés por los medios en su versión digital fueron trabajados en géneros como la noticia.

Como solo se estudió la noticia del día en el cual ocurrió el hecho, no se observaron otros géneros periodísticos que permiten profundizar en los hechos, como el reportaje y la entrevista. Queda para otras investigaciones indagar sobre el tratamiento integral, desde el punto de vista periodístico, de este tipo de hechos en días subsiguientes al momento ocurrido.

El resguardo de la persona y la dignidad humana como valor intrínseco del ser quedaron vulnerados. En algunos de los casos estudiados, los medios 
incurrieron en colgar videos y fotografías de los hechos que reproducían el momento en el cual las víctimas fallecían. Prevaleció ganar seguidores en una acción sensacionalista, comercial y de irrespeto, que salvaguardar la imagen no maltrecha de las personas, que lamentablemente murieron en las protestas. La dignidad humana no solo se suscribe a la persona viva, en su esencia; aunque esté muerta, a su alrededor existen familiares, amigos, ciberlectores que pueden impactarse con lo divulgado.

Los medios en el mundo 2.0 mantienen una línea sensacionalista del periodismo, el suceso la clásica página roja se maneja en la plataforma virtual con los mismos criterios de los impresos de llamar la atención, sin importar valores como el respeto, la dignidad y el apego a lo humano.

\section{Referencias}

Abad, F. (2010). Filosofía política de la responsabilidad socialista en materia de comunicación. Conatel.

ABC. (17 de octubre de 2009). "Toda fuente miente mientras no se demuestre lo contrario", dijo Restrepo. ABC. https://www.abc.com.py/articulos/toda-fuentemiente-mientras-no-se-demuestre-lo-contrario-dijo-restrepo-31603.html

A Favor de lo Mejor. (2004, marzo). Sobre la autorregulación. Catholic.net. http://es.catholic.net/op/articulos/27417/sobre-la-autorregulacin.html\#modal

Amón, R. (2016, 17 de noviembre). 'Posverdad', palabra del año. El País. https://elpais.com/internacional/2016/11/16/actualidad/1479316268 308549.ht $\underline{\mathrm{ml}}$

Ardèvol-Abreu, A. (2015). Building the agenda and news frames about countries facing humanitarian crises: news values and selection of information sources. Communication y Society, 28(1). https://doi.org/10.15581/003.28.1.43-62

Aruguete, N. (2017). El poder de los medios en la política. Historia crítica de la Agenda Setting. Programa de Seminario de Doctorado. Universidad de Buenos Aires. http://www.sociales.uba.ar/wp-content/blogs.dir/219/files/2017/02/Aruguete.pdf 
Asamblea Nacional de la República Bolivariana de Venezuela. (2011). Ley de Responsabilidad Social en Radio Televisión y Medios Electrónicos. Gaceta Oficial N. ${ }^{\circ} 39$ 610. http://www.conatel.gob.ve/files/leyrs06022014.pdf

Así se vive en las redes sociales las protestas en Venezuela. (2017, 20 de abril). El Nuevo Herald. http://www.elnuevoherald.com/noticias/mundo/americalatina/venezuela-es/article145446614.html

Aznar, H. (1999). Comunicación responsable. Deontología y autorregulación de los medios. Ariel.

Bracci, L. (2017, 27 de julio). Lista de fallecidos por las protestas violentas de la oposición venezolana, abril a julio. Alba Ciudad Digital. http://albaciudad.org/2017/o7/lista-fallecidos-protestas-venezuela-abril-2017/

Canelón, A. (2008). Periodismo, gerencia y conocimiento. La experiencia de los consejos editoriales de El Nacional. Comunicación: estudios venezolanos de comunicación, $144,42-51$.

Cerviño, B. (2013). El uso de las redes sociales como fuentes de información para periodistas [monografía de máster, Universidad Autónoma de Barcelona]. http://www.recercat.cat/bitstream/handle/2072/216886/Versi\%C3\%B3n\%2odigit al\%20del\%20trabajo.pdf?sequence=1

Conatel. (2015). Indicadores del servicio de Internet a nivel nacional 1998-2015. Observatorio Estadístico. http://www.conatel.gob.ve/estadisticas-anuales-ytrimestrales/

Congreso de la República de Venezuela (1995). Ley de Ejercicio del Periodismo. Gaceta Oficial n. ${ }^{\circ} 4883$. http://cdn1.cnpven.org/archivos/73/original_ley_ejercicio_periodismo.pdf

Consejo Nacional de Periodistas. (2013). Código de Ética del Periodista Venezolano. XV Convención Nacional de Caracas. CNP, Caracas, Venezuela. http://cdn1.cnpven.org/archivos/80/original codigoeticafinal.pdf

Constitución de la República Bolivariana de Venezuela. (2009). Gaceta Oficial N.$^{\circ} 5.908$ extraordinario. Ediciones de la Asamblea Nacional. 
Ferreira, M. (2017, 31 de marzo). Fiscal denunció "ruptura del orden constitucional” tras sentencias del TSJ. El Universal.

http://www.eluniversal.com/noticias/politica/fiscal-denuncio-ruptura-del-ordenconstitucional-tras-sentencias-del-tsj 646250

Freitas, L. (2016). Periodismo ciudadano: un nuevo paradigma comunicacional. Factum. Universidad Católica Andrés Bello. http://w2.ucab.edu.ve/periodismo-ciudadanoun-nuevo-paradigma-comunicacional.html

García, X. Silva, A. y Torel, C. (2014). El periodismo en tiempos de las redes sociales: retos y desafíos para viejos y nuevos profesionales de la información que se subieron a Twitter. Actas del VI Congreso Internacional Latina de Comunicación Social. Universidad de La Laguna. La Laguna, Tenerife. http://www.revistalatinacs.org/14SLCS/2014 actas/o15_Lopez.pdf

González, C. (2012, de diciembre). Historia del periodismo ciudadano en el mundo. Periodismo ciudadano en Venezuela. http://periodismociudadanovenezuela.blogspot.com/2012/12/historia-delperiodismo-ciudadano-en-el.html

Guedez, V. (2008). Ser confiable. Responsabilidad social y reputación empresarial. Planeta.

Iglesias, J. (2015, 22 de julio). ¿Cómo consumimos noticias de actualidad a través de las redes sociales? Zesto. https://www.zesto.es/noticias-redes-sociales-informacion/

Izarra, A. y López F. (2010). Los guardianes del periodismo pornográfico. La deriva pornográfica del periodismo: "Si sangra, encabeza". https://es.calameo.com/read/000035112b836e3d12175

Korin, M. (2011). Los medios de comunicación. En la responsabilidad social de la empresa en América Latina. Fondo Multilateral de Inversiones (FOMIN) BID

Lobos, S. (2018, 24 de enero). Papa a los periodistas: "Sean custodios de noticias y busquen la verdad". VaticanNews.

http://www.vaticannews.va/es/papa/news/2018-01/mensaje-del-papa-franciscojornada-mundial-de-comunicacion-2018.html

Revista Análisis

ISSN: 0120-8454 | e-ISSN: 2145-9169 | DOI: https://doi.org/10.15332/21459169

Vol. 53 N.o 98 | enero junio de 2021 
Lucas, K. (2008, 22 de enero). Apuntes sobre la responsabilidad, la veracidad y la transparencia en los medios de comunicación. Rebelión.

https://rebelion.org/apuntes-sobre-la-responsabilidad-la-veracidad-y-latransparencia-en-los-medios-de-comunicacion/

Martín Barbero, J. (1998). Medios: olvidos y desmemorias. Revista Número, 24. http://www.olavarria.com/ciudad/universitarios/biblioteca/descargas/b/barbero \%20sobre\%20Medios.pdf

Observatorio Venezolano de Conflictividad Social. (2017). Venezuela: 6729 protestas y 163 fallecidos desde el 1 de abril de 2017.

http://www.observatoriodeconflictos.org.ve/destacado/venezuela-6-729protestas-y-157-fallecidos-desde-el-1-de-abril-de-2017

ONU. (2017). Informe sobre el $2 O^{\circ}$ periodo de sesiones. [Documento oficial E/2017/31E/CN.16/2017/4]. http://unctad.org/meetings/es/SessionalDocuments/ecn162017d4_es.pdf

Real Academia Española. (2017). Posverdad. En Diccionario de la lengua española (edición de tricentenario). Consultado el 17 de julio del 2019. https://dle.rae.es/posverdad

Rodríguez, R. (2009). La agenda de los alumnos en clase, profesores como medios y agenda-setting. Estudios sobre el Mensaje Periodístico, 15, 431-442. https://revistas.ucm.es/index.php/ESMP/article/view/ESMPogog110431A

Rubio, J. (2009). Opinión pública y medios de comunicación. Teoría de la agenda setting. Gazeta de Antropología, 25, 1-10. http://www.ugr.es/ pwlac/G25_01JoseMaria_Rubio_Ferreres.html

TSJ de Venezuela aclara sentencia sobre la AN para superar impasse entre poderes públicos (2017, 1. ${ }^{\circ}$ de abril).. Telesur. https://www.telesurtv.net/news/TSJ-deVenezuela-corrige-sentencia-sobre-funciones-de-Parlamento-20170401-0016.html

Valenzuela, S. y Halpern, D. (2015, abril). Un estudio sobre el impacto de las redes en las actividades de los periodistas, las noticias y la industria informativa [presentación de diapositivas]. TrenDigital, Pontificia Universidad Católica de Chile. http://comunicaciones.uc.cl/wpcontent/uploads/comunicaciones/2015/04/periodismo-y-redes-sociales-PDF1.pdf 
Yapur, N. (2015, septiembre 24). ¿Cuáles son las redes sociales más usadas en Venezuela? [Página web]. El Estímulo. https://elestimulo.com/elinteres/cualesson-las-redes-sociales-mas-usadas-en-venezuela/ 